\title{
LEADERSHIP STYLE DURING TRANSITION IN SOCIETY: CASE OF ESTONIA
}

Ruth Alas

Estonian Business School, Estonia

\author{
Külliki Tafel \\ Estonian Institute for Futures Studies, Estonia \\ Krista Tuulik \\ Estonian Business School, Estonia
}

\begin{abstract}
Leadership is culturally contingent and the status and influence of leaders vary considerably as a result of cultural forces in the countries or regions in which the leaders function. And not only cultural but also economical transition has impact on leadership. During the last fifteen years Estonia has transformed from being an authoritarian, centralized, totalitarian socialist state, to a democratic country with a free market economy and different attitudes and values. During economic transformation a complex set of normative and operating principles, embodied in historical structures, systems and practices becomes replaced by another unknown set, providing its members with a very ambiguous and uncertain period. the challenge has been to internalize a new type of organizational behavior in order to operate successfully under unfamiliar conditions. During this period of transformation actors, including top managers had to learn to deal with the discontinuities of the institutional environment. Authors analyze leadership styles of top managers of Estonian companies by using different theories of leadership as theoretical framework. The analysis is based on empirical data from international GLOBE study initiated by Robert House. GLOBE is a long-term project directed toward the development of systematic knowledge concerning how societal and organizational cultures and subcultures affect leadership and organizational practices (House et al. 2004). It includes a short CEO questionnaire on management preferences and strategies. In addition, a number of up to nine followers have been asked to describe the leadership style and behavior of their CEO with a questionnaire from the GLOBE. Questionnaires were translated and re-translated into Estonian language. The questionnaire asks for leadership behavior, trust and confidence of the followers, and their perception of the objectives and strategies of the firm. 53 questionnaires completed by the CEOs and 324 questionnaires were completed by subordinates. First, the content analysis of interviews was
\end{abstract}

done, in order to find out leadership styles. Second, cluster analysis was performed by cases to classify CEO-s. Statistically significant differences were found out by using ANOVA test. The content analysis of interviews brought out following styles: autocratic style (15\% of respondents), transactional style (31\%) and transformational style (48\%). There were also some traits of authentic and servant leadership. Authors develop implications for leadership development in countries in transition.

\section{INTRODUCTION}

Although there is no substantial change in this side, that leaders achieve results through the others work, there are still differences in the way, and how leader achieves this. Leadership is culturally contingent and the status and influence of leaders vary considerably as a result of cultural forces in the countries or regions in which the leaders function. And not only cultural but also economical transition has impact on leadership. Transformation from being an authoritarian, centralized, totalitarian socialist state, to a democratic country with a free market economy is a process, in which a complex set of normative and operating principles, embodied in historical structures, systems and practices becomes replaced by another unknown set (Clark and Soulsby 1999: 18). It provides its members with a very ambiguous and uncertain period. During economic transformation the challenge has been to internalize a new type of organizational behavior in order to operate successfully under unfamiliar conditions. During this period of transformation actors, including top managers had to learn to deal with the discontinuities of the institutional environment.

Authors analyze leadership styles of top managers of Estonian companies by using different theories of leadership as theoretical framework. Leadership in the East European transitional countries have been seen as more autocratic and less participative, less human and more status oriented and, at least partly, more formal (Alt et 
al 2003). The aim of the article is to identify the possible change in leadership styles among Estonian top managers. The research question here is about Estonian top managers' possible movement towards more "softer" style of leadership during the years of transition. The analysis is based on empirical data from international GLOBE study. The empirical study involved interviews with CEOs of 63 companies and questionnaires completed by the CEOs and their subordinates. In this article the short theoretical overview is followed by content analysis of interviews and implications for leadership development in countries in transition.

\section{THEORETICAL BACKGROUND \\ Defining Leadership}

From theoretical literature one could find a whole range of different definitions for the concept of leadership. It can be argued that there is no precise definition or widely accepted vocabulary for describing and discussing this phenomenon. Burns (1978: 2) also indicates that there is no school of leadership, intellectual or practical. According to House \& Aditya (1997: 409, 462), almost all of the prevailing theories of leadership are rather distinctly American in character and in addition, these theories do not address the issue as to whether they can be generalized to other cultures.

Leadership is the complex phenomenon involving the leader, the followers, and the situation. Yukl (1989; 252) points to Stogdill (1974) who argues that "there are almost as many definitions of leadership as there are persons who have attempted to define the concept". Yukl (Ibid.) indicates that leaderhip has been defined in terms of individual traits, leader behavior, interaction patterns, role relationships, follower perceptions, influence over followers, influence on task goals, and influence on organizational culture.

In defining leadership the question about its relatedness, its similarity to management and difference from it comes along quite often. In relation to management one of the most cited definitions comes from Bennis and Nanus (1985). They (Ibid. 21) claim that if managers are people who do the things right, then "... leaders are people who do the right thing."

Ciulla (2004b) has pointed that leadership is a distinct kind of moral relationship. Leaders cannot empower people unless they have the moral courage to be honest and sincere in their intention to change the power relationship with followers. First, they must be honest with themselves. On the other hand, additionally, people want leaders who are honest, forward-looking, competent and inspiring (Kouzes, Posner 2003).

Referring to Kotter (1990) the 'direction setting' is an important aspect in leadership. He (Ibid.) adds that direction setting is a process that produces vision and strategies and is more sophisticated in essence than plain organizing or planning. Kotter (Ibid.) emphasizes a key aspect of leadership as alignment - getting people to understand, accept, and line up in the direction chosen. Kotter (Ibid.) sees also the motivation and inspiration as key aspects of leadership and argues that leadership functions may require more than one person. Yukl (1994: 4) points that leaders are oriented toward innovation and try to "...get people to agree about what things should be done." The leader's job is to create conditions for the team to be effective (Ginnett, 1996).

\section{Leadership styles}

Although there is no substantial change in this side, that leaders achieve results through the others work, there are still differences in the way how leader achieves this. Started from 1980's the term 'inspire' is included. From one side it indicates different sources of power leaders' use. From other side it brings us to development processes inside of leadership.

According to Eagly \& Johannesen-Schmidt (2001: 786), Bales (1950) introduced the most common distinction of leadership styles: task-oriented style, defined as a concern with accomplishing assigned tasks by organizing taks-relevant activities, and interpersonally oriented style, defined as a concern with maintaining interpersonal relationships by tending to others' morale and welfare. This distinction of leadership styles was developed further. Into the task-oriented style the following behavior was included: encouraging subordinates to follow the rules and procedures, maintaining high standards for performance, and making leader and subordinate roles explicit. The behavior such as helping and doing favors for subordinates, looking out for their welfare, explaining procedures and being friendly and available was included into interpersonally oriented style.

Eagly \& Johannesen-Schmidt (Ibid. 786, 787) point also to another aspect of leadership style: the extent to which leaders behave democratically and allow subordinates to participate in decision making or behave autocratically and discourage subordinates from participating in decision making. This democratic versus autocratic leadership is similar to the dimension of participative versus directive leadership. 
Eagly \& Johannesen-Schmidt (Ibid. 787) claim, referring to Bass (1998) that in the 1980s and 1990s many researches turned their attention to other types of leadership styles by distinguishing between leaders who are transformational and those who are transactional. This effort was initially inspired by Burns (1978: 4) who identified two basic types of leadership: the transactional and transforming. He finds (Ibid.) that most of the relations between leaders and followers are transactional - leaders approach to followers with an eye to exchanging one thing for another: jobs for votes, or subsidies for campaign contributions, etc. Burns (Ibid.) also points to the third type of leadership - moral leadership.

Although theoretical literature describes different approaches to the division of different leadership types, there are some most frequently discussed leadership styles in literature:

$\checkmark$ Authoritarian leaders use legitimate power based on their formal position in organization's hierarchy. The keywords for identifying this style are: usage of power, formal relationships, the existence or importance of hierarchy.

$\checkmark$ Transactional leaders use reward and cohesion power in exchange process in order to satisfy immediate needs (Burns 1978). They ensure through the use of rewards and sanctions that followers the followers perform the required behaviors. It is like social exchange: leaders can offer resources to followers in exchange for the followers' compliance and the loyalty to the leader (Kanungo and Mendonca, 1996). The focus of the transaction influence process is solely on the leader's objectives, needs and concerns (Kanungo and Mendonca, 1996). Transactional leadership involves reinforcement: leaders either make assignments or consult with followers about what is to be done in exchange for implicit or explicit rewards and the desired allocation of resources (Bass and Steidlmeier, 2004). The central traits of this style can be summed up as follows: reward-based, exchange-based, importance of self-interests.

$\checkmark$ Transformational leadership, in contrast, concentrates on satisfying higher needs (Burns 1978). It is about bringing a change in the followers' attitudes and values (Kanungo and Mendonca, 1996). Transformational leadership is motivating, uplifting and more ethical (Burns 1978). Transformational leadership consists of charisma (idealized influence), inspirational motivation, intellectual stimulation and individualized consid- erations (Bass 1985).

- Servant-leaders number one priority is to serve others - including employees, customers and community (Greenleaf, 2002). They differ from other persons of goodwill because they act on that they believe. They have following characteristics: listening, empathy, healing, awareness, persuasion, conceptualization, foresight, stewardship, commitment to the growth of people and building community (Spears 1998).

$\checkmark$ Authentic leaders genuinely desire to serve others through their leadership. They are as guided by qualities of the heart, by passion and compassion, as they are by qualities of the mind. They lead with purpose, meaning and values and build enduring relationship with people. They are consistent and self-disciplined. They are dedicated to developing themselves. After failure of current corporate governance system brought out by Enron scandal, George (2003) points out need for the new generation leaders: for leaders committed to stewardship of their assets and to making a difference in the lives of the people they serve. To become authentic, each has to develop own leadership style, consistent with personality and character. Over time this style need to be developed, in order to be effective in leading different types of people and to work in different types of environments (George 2003).

The authors apply these leadership styles in the analysis of the Estonian CEOs' leadership styles.

\section{METHODOLOGY}

The authors conducted CEO study in Estonia. The CEO study is part of the Global Leadership and Organizational Behavior Effectiveness Research Program (GLOBE project). GLOBE is a long-term project directed toward the development of systematic knowledge concerning how societal and organizational cultures and subcultures affect leadership and organizational practices (House et al. 2004). The CEO project includes self perceptions of the managers and also leadership behaviors as seen from the followers. The CEO study shares the main theoretical assumptions of the GLOBE project as a whole. Leadership is seen as socially constructed by managers and followers as well as by culturally based assumptions of a society. Socialization theory supports the idea of a learned behavior, which is supported by role models from the past and the present in politics and economy. Successful leadership requires therefore acceptance of the style by the followers, and is in turn the result of leader's success. According to contingency theory, the organiza- 
tional context plays also an important role, but mainly as a mediator of societal influences (Alt et al 2003).

The empirical study involved two hours interviews with CEOs of 63 Estonian companies, which included questions concerning leadership career, experiences and philosophies, as well as change management. The interviews contained both direct and indirect questions enabling to make conclusions on the leadership styles of the Estonian managers. When making conclusions the authors used the answers to selected particular questions and also made use of the "general atmosphere" of the interview: the manner of responding to the questions, the terms used the emphasis etc. In addition, a number of up to nine followers have been asked to describe the leadership style and behavior of their CEO with a questionnaire from the GLOBE. Questionnaires were translated and re-translated into Estonian language. The questionnaire asks for leadership behavior, trust and confidence of the followers, and their perception of the objectives and strategies of the firm. 53 questionnaires completed by the CEOs and 324 questionnaires were completed by subordinates. 20 CEOs were owners of entrepreneurial firms and 20 CEOs were not owners. Heads of divisions in domestic companies were not considered CEOs and did not qualify for inclusion in the sample.

The sample used for the current research, consisted of $60 \%$ men and $40 \%$ women, whose average (mean) age was 36.9 years. The majority of respondents $(61,7$ $\%$ ) had a university degree. The majority of CEOs (38 $\%$ ) belonged in the 31-40 age group, followed by the age group 41-50 years (29\%), and the per-cent of CEOs belonging to the age groups 20-30 and 51-60 was practically equal (13\% and $14 \%$ respectively). Of the subordinates reporting directly to the CEO, $58 \%$ belonged in the 31-40 age group. According to positions in the companies, $17 \%$ of subordinates were working in sales and marketing, $15 \%$ in the finance department and $13 \%$ in operations.

\section{ANALYSIS}

The content analysis of interviews was done, in order to find out the leadership styles common to Estonian leaders. In content analysis the authors used the four leadership styles most frequently discussed in the theory (Autocratic, Transactional, Transformational and Authentic). By interpreting the CEOs' responses the authors attempted to reach an understanding of which leadership styles can be most frequently referred to in case of the Estonian managers.

When interpreting the interviews the authors consider the following contextual circumstances concerning
Estonia. Since Estonia is a transition country (at least it definitely was in the period of carrying out the interviews in 2001), this means that at least the following circumstances should be considered while linking the interviews to theory.

On the one hand the authors find that in transition countries the changes in the economic environment and in the related institutional and social environment occur here faster than in the countries with a developed economy and in the developing countries, the various styles of leadership could be quite well identified in this particular context. The variety of leadership styles in existence and in use can be presumed to be greater. This means: the authors would rather expect a more varied than homogeneous body of styles.

On the other hand, considering the constant state of change, typical of a transition country, it is quite likely that obvious signs of any clear-cut style of leadership would be difficult to find. One could presume that a mixed style and "swinging" between various styles would be more likely than definite signs of a clearly identifiable style. It is necessary to point out that the absence of the so-called "pure" styles is not a characteristic feature of a transition country, but is a more general phenomenon: any "pure" models would be placed in any actual context. It can be presumed, however, that this "inconsistency" would be more emphasized in case of a transition country.

Thirdly, when interpreting the emergence of various styles based on the interviews, the following aspect should be considered: in the case of a transitional economy we should not overlook the aspect (at least in the early years) of concentrating on rapid economic development where the social side will (inevitably) be left in the background and economic development will take place at the expense of social and environmental development. In other words: in case of the transition countries it is the general context and situation, which largely define the manner of operation and the styles the managers can use. The latter cannot be considered a complete justification, yet it cannot be discarded either when making conclusions about the identified styles.

A general conclusion of the content analysis of interviews is that different leadership styles can be identified among Estonian leaders, but certain variations exist compared to theoretical treatment. While the various styles identifiable according to the responses of the Estonian entrepreneurs largely coincided as to the basic features, they were so peculiar that it would have been too complicated to classify then in accordance to the theory. The latter also led to the fact that the 
authors, while proceeding from the styles described in the theory, combined (concentrated) the styles and modified them according to the responses.

When interpreting the interview results the authors faced the following problematic aspects. First, the differentiation between the authoritarian and transactional styles turned out to be somewhat complicated. The styles, clearly identifiable in theory, were somewhat difficult to pin down in case of the Estonian managers, partly because the moment of exchange, central to the transactional style on the one hand, and the moment of formality, typical of the authoritarian style on the other hand, were hard to identify in a clear and direct manner.

The recognition of the transformational style also turned out to be problematic - the Estonian managers can only conditionally and partly be classified according to this style of leadership. I.e., not all features characterizing this style are typical of the leader classified as such, but predominantly only some of them. In the classification of the Estonian CEOs the authors proceeded from clear hints received from the interviewees' attitudes and their statements to "developing from" more or less authority-based styles. Briefly, the CEOs classified according to this style of leadership should be viewed as moving towards the transformational style, but difficult to characterize as having features typical of transactional and authoritarian styles.

The interviews' results enable to refer to some very rare similarities to the authentic style. Still, based on the interviews' analysis one has to admit that the interviews do not enable to determine the presence of the servant or authentic styles among the Estonian managers.

Despite the difficulties with the classification of the Estonian CEOs according to the various, theoretically most widespread leadership styles, the interviews enable to define two quite clearly different types. According to the interview results, to characterize the leadership styles among Estonian CEOs, the authors submit a binary classification instead of the quadruple (quintuple) classification. On the one hand the authors differentiate the leadership style based on authority, which combines the authoritarian and transactional styles and on the other hand, the transformational style or one close to it.

\section{Estonian CEOs: independent decision makers and team players}

According to the analysis of the interviews the authors combine the authoritarian and transactional styles to a common denominator, defining it collectively as the independent decision maker style. A CEO using the independent decision maker style is characterized by the central feature of use of authority, which means proceeding from one's own opinion, making oneself the central figure, being tough, but also tackling problems on one's own and interfering.

The interviews characterize several common aspects and principles, which are typical of the CEOs belonging to this group of leadership style. The authors shall further point out the aspects, which were most decisive in the responses of the interviewees classified as independent decision makers. It is the most obvious from their style of communication and perception of leadership as such.

The communication style of a CEO practicing the independent decision-making style reveals a quite clear differentiation between the boss and the subordinate, talking to a subordinate rather than with the subordinate. The CEO belonging to this group views no need to involve other employees in decision-making or the realization of changes; any new activities or directions will be made clear to the staff. Referring to interviewees: "... I have acquainted [the authors' emphasis] the staff with all changes before their realization..." (EM007); "... it is important that the strategy and mission, the values and goals of the whole organization be defined and set. And it should be presented [the authors' emphasis] to everybody, what we want to achieve..." (EE012).

The authors point out here that the mere acquainting of the staff with the organizational changes, goals etc. do not refer to the involvement of the staff in the process or the discussion of the matter with them. "The matters" shall be first decided by the CEO and the staff will only then be informed of them. The responses in the interviews can be interpreted as the CEOs' behavior, where the managers do not consider the employees' ideas or recommendations useful and do not find that they could be of any use.

The second aspect perceived in the interviews and characteristic of this type of manager is that they use persuasion for winning the other employees' support to a decision made by them. As explained by one of the interviewees, when executing changes one needs to: "first carry out the so-called internal marketing or make sure that there is a critical mass of people, who accept the change and consider it right" (EM015) - in other words, to sell their idea to the other employees. If the employees would not accept the changes, 
according to an interviewee, it just should be repeated to them one more time: "... of course there were people, who did not want to accept the change. But we discussed it one more time with these people..." (EM024). To sum it up: the statements of the CEOs of this group reaffirm the previously mentioned idea that the ideas declared by the managers are meant to be accepted rather than discussed.

The independently deciding CEOs either do not overly emphasize the asking of the employees' opinion or always reserve the right to make the final decision. Cooperation with the employees is perceived as something where the CEO need not change his position, attitude or perception of anything. As the respondents tellingly described: "At the same time one can say that in order to do it successfully, one should ask for the opinions of all subordinates, I mean specialists and managers and to discuss and to talk with them because these people have been working in public transport for a long time and would not say something stupid. " (EM030); "... in reality the subordinates should make proposals about better ways of working and I shall then decide whether the proposals are realistic or not... ." (EM046); "I listen to a lot of people, but make my own decisions. I do not punish anyone, who thinks differently ...." (EE052) and "I am a team man. [But] I am not willing to agree and be tolerant in the sense that the people, whose world-view is different [from mine] ... ." (EE047)

Representative of this style attempts to justify (without really providing one) that the CEO must be tough by nature: "... a manager can never be too mild and I have never tried to be..." (EE010). When discussing leadership as such they emphasize the importance of monitoring: "... and it is our [the managers'] business to monitor this ..." (EE012); up to outright questioning of the other workers' ability to do anything: "... only if I have done it myself I know that it has been done right..." (EE014).

A feature, which is not directly reflected in the authoritarian and transactional styles described in the theory, was quite emphasised in the interviews carried out with the Estonian CEOs and emerged as a characteristic feature in case of interviewees representing this style, is the desire to do it oneself and to interfere. Quoting the interviewees: "... [would want to] $d o$ everything myself; ... [would want to] to be informed, to know everything and to make decisions..." (EE016). Briefly, these examples expressed the desire of the managers in this group to use authority in leadership in different ways. As one of the respondents remarked: "...by taking advantage of my position I attempt to force the guys to sit down and discuss matters ..." (EE025).

To sum it up, a CEO using the independent decisionmaking style, attempts to make his own person central by taking advantage of the authority granted by his position and justifying it with a claim that the other employees would not be much use anyway in submitting opinions. When comparing it with theory, the ways of characterising the transactional and authoritarian types, the independent decision-making style reveals quite clearly a combination of features typical of these two styles. Usage of power, importance of hierarchy (in the context of superior-subordinate relations), as well as importance of self-interests are all quite common to the independent decisionmaking style.

The other separate group is formed by the respondents, who can be characterised by the keyword "team". As the authors pointed out already, these respondents could be considered close to the transformational style. Since it is difficult to attribute to them many of the features typical of the transformational style, the authors designate the leadership style of the CEOs of this group as that of team players. The keywords emphasized by the team player CEOs is granting the staff latitude in their work, hearing their opinion, involving them in decision-making, etc.

The idea of leadership of a team player style CEO differs from that of an independent decision maker type to a significant degree. Let us quote the respondents: "Leadership is not a large number of people but an issue of responsibility. I do not have a single director in the firm designated as such. The responsibility of a director is limited to sending out directives and checking compliance with the directives ... Very frequently there is a psychological aspect that as we appoint someone director, he begins very intensively to check the others and send out directives and the process of promoting initiative among the employees disappears and things become really bad then." (EE001) and "it is my task to contribute ... to find in the enterprise these resources and to train and motivate the staff to do their work well." (EE021)

Another aspect, which the CEOs representing the independent decision-making style never express in principle, is the attitude typical of the team players, where the others are viewed as guarantors of one's success or where the manager claims that he could not work without the others. Some quotes: "I am such a team player ... I can achieve with a team more than alone and it is important for me to have people around 
me ... it works if the staff can get along well. This does not mean that we always agree and never argue and we sometimes have serious arguments, but I believe that this is for the best." (EM008) and "Teamwork is our strongest feature, the way the organization works and operates as a team, that the weaker members are supported ... if you can see that somebody cannot take the strain, it always happens in creative work that people sometimes get tied and grow weaker, then they should be supported, ... they should be granted some respite instead of being immediately fired... ." (EM034)

Another aspect in case of CEOs with this style of leadership is their tendency not to set themselves apart, at a higher level, but to stay at the same level as the rest of employees. The respondents themselves expressed this as follows: "... not to be apart of the collective and act "like a big boss". I find that myself as the manager and my deputies, regardless their position, should not always enforce their own line but in any complicated situation contribute to the solving of the problem, instead of staying aside they should help and encourage the collective and the employees. My role on the one hand is to manage and direct ... at the same time to help... ." (EE021)

The importance of monitoring, which was of quite central importance for the independently deciding CEOs, is starting to lose its significance for the team players. According to one of the interviewee: "one should allow the employees to work as freely as possible. The more freedom they have, the better can they handle their work and the better results will the firm achieve." (EM 020)

The managers of this type are also characterized by involving their staff in the process of realization of changes or making decisions, rather than merely informing them of already determined changes. The following interviewee described it quite figuratively: "in the ideal case these moves would be undertaken only after sufficient preparatory work. If we are in some ... say organization and the same people within this organization will carry out the changes, one first has to prepare for the change with same people. Instead of first doing the changes and then saying that listen, friends, you will do this tomorrow, he will do that etc... ." (EM035)

The interviews' results usually enable to point out an evolved version of the teamplayer style. Besides the previously listed features, the latter version is characterised not just by an understanding of the need for cooperation and emphasis on listening to people, but also the motivation of the staff, individual approach etc. "The employees succeed only if their activity is publicly recognised, then they are always more efficient. If their achievements are acknowledged within the working process, this means that they have committed their creative effort to the development of the process." (EE001) and "starting with the manager's role, one has to work with the employees. One has to do a lot of work with the staff. One has to find some personal approach to everyone - Mari likes this and Peeter likes that. One has to identify himself with the employee so as to deal with him." (EM018)

Some individual answers (answers rather than the respondent's entire nature and attitudes) quite clearly reflect transformational style or even authentic leadership style: "I am just ... a missionary type. I lack that sufficient consistency, a weakness for control. I find it hard to talk to people in a tough or aggressive manner. I want to think first whether I am fair. I dare admit my mistakes ... and I am trying to encourage others to do the same. One needs a vision and this is not my individual vision, this is a common vision with colleagues. I am one of them. Trust yourself and others, be open and do not fear to show your vulnerability. I am trying to acknowledge people rather than criticise them. It is important to me that they dare openly admit their faults or mistakes because they would not be punished for that." (EE002)

Generally, in case of the teamplayer style the central position of hierarchic structure (superior-subordinate) as well as of the aspect of monitoring have lost their significance, it has been replaced by the involvement of the employees, considering them, hearing out their opinion etc. If we refer to the descriptions provided by the theory we can point out the similarity between the typical features of the teamplayer style and the central keywords of the transformational style. The keywords such as importance of motivating, attaching importance to values, stimulating intellectually, etc. also are to a greater or lesser degree central in case of the teamplayer style.

An interesting difference between the two previously described groups of CEOs emerged from the responses to the question asking the respondents to list their strengths of character. The respondents, who could be classified as practicing the independently deciding leadership style, predominantly had no problems with the expressing of their strengths, which they expressed in a quite matter-of-fact and certain manner. The following contains examples of answers by respondents classified as the independent decisionmaker style: "A strength of character is a well-developed "gut feel- 
ing", intuition. A powerful vision, knowledge of what will happen in future. Being active is another strength. As well as good communicating ability. I am sufficiently purposeful. One of my strengths is also the ability to motivate." (EE012)

At the same time the teamplayer type CEOs became reticent when answering that question and listed their characteristic abilities quite hesitantly. To quote the respondents: "... a tough question ... if a goal has been set, I find that it must be achieved, not necessarily at any cost, but we got to do what we have promised." (EE021) and "Strengths of character ...well, God forbid. I am not sure that I even have any? ...Then I think that when relating to people I can also hear them out and understand them ... ." (EM043)

To sum it up, the authors find that these two distinct styles defined according to the interviews - the independent decisionmaker and the teamplayer - have significant differences. Estimates of how many interviewees could be classified as representing either style enable to conclude, albeit with some generalisation, that the Estonian CEOs are principally divided fifty-fifty as to these two leadership styles.

An interesting feature emerging from the interviews was the CEOs' wish to be "worse" rather than "better". I.e., many Estonian CEOs tending towards the transformational type expressed a desire or wish to act in a more self-centred manner, to be more authoritarian and less democratic. Their "softness" was often described as the corresponding person's weakness of character. Some quotes from the responses: "[I consider my weakness that] I am not an authoritarian $C E O$... and thus maybe is incapable of abruptly saying no to everybody" (EE021) and "I am too compliant, I should be tougher and more resolute as a manager..." (EE027).

Finally, besides the results of the interviews providing a somewhat different image of leadership styles as compared to theory, an interesting aspect reflected from the responses of several interviewed Estonian CEOs was the desire and also the need for using, instead of the complicated and many-faceted leadership styles, the more self-centred and essentially less complicated ones.

\section{CONCLUSIONS}

\section{AND DISCUSSION}

The leadership styles defined in theory - authoritarian, transactional, transformational, servant and authentic were reflected in the interviews with certain variations. When placing the results of the interviews in the context of the leadership styles presented in theory, it became necessary to combine (concentrate) and modify them to certain extent. All in all, the authors defined regarding the interviewed Estonian CEOs on the one hand the so-called independent decisionmaking and on the other hand teamplayer styles. The authors found that these two styles differ from each other in a significant degree.

The emergence of two "modified" leadership styles from the analysis of the interviews instead of the four discussed in theory could be interpreted as a weakness of coinciding aspects between the outcomes of the interviews and the theory. This conclusion is certainly further supported by the fact that the Estonian CEOs are rather difficult to classify as to individual styles defined in theory. It should be added, however, that the authors cannot rule out the possibility of the partial scarcity of coinciding aspects being caused by the selection of questions asked in the interviews or their emphasis. This in effect means that another methodology (questions) could have yielded different outcomes.

On the other hand, despite the absence of the four leadership styles according to the theory, the coincidences of the theory and the interview results should be judged as relatively good. Admitting certain variations, the keyword-based essential identity between the transactional and authoritarian and the independent decisionmaking styles as termed by the authors on the one hand, and between the transformational and teamplayer styles on the other hand, is quite significant. Thus the independent decisionmaking style and the authoritarian and transactional styles are identically characterised by keywords like usage of power, importance of hierarchy (in the superior-subordinate relationship context), importance of self-interests etc. Alternatively, the teamplayer and transformational styles can be characterised by the keywords like importance of motivating, attaching importance to values, stimulating intellectually, etc. All in all the aspects of hierarchic (superior-subordinate) relations, as well as that of control, which occupy a central position in the independent decisionmaking style have lost their significance in the teamplayer style; they have been replaced by the involvement of the employees, considering them, hearing them out and other such considerations.

The outcome of the interviews, which revealed that the independent decisionmaking and teamplayer styles are basically equally represented among the Estonian CEOs turned the interviews' results into a positive surprise for the authors. Proceeding from the context of 
Estonia as a transition country, where rapid economic development has driven the more social aspects to the background, one could have presumed that the Estonian CEOs would predominantly represent the leadership styles based on the element of authority and less the ones concentrating on cooperation, teamwork, motivation of staff, individual approach etc. When making generalisations about the eastern European transition countries it is pointed out that in their case a more autocratic and less participative, less human and more formal leadership style is predominant.

The outcomes of interviews made with the Estonian CEOs reveal a certain shift in the perceptions of the managers, which either has taken place or is in the process of occurring: about how - in which ways and by which methods - to lead. In a more general way the results outline a more broad-based and extensive change, where the general social stability enables the CEOs to use a softer and more involving leadership style (unlike the period of rapid changes at the early years of transition, where the surrounding environment confronted the CEOs with situations, where they were "forced" to make most of the decisions on their own).

The clear emergence of the teamplayer style, as the authors described it, in case of the Estonian CEOs shows that a certain number of enterprises-organisations in Estonia have reached a stage of development (where the management of processes e.g. is more complicated), which presumes a different, incl. more involving, softer etc. leadership style. At the same time the parallel existence of the independent decisionmaking style can be interpreted on the one hand with a continued period of changes, instability or at least uncertainty in the enterprises, which partly presumes the use of this less team-oriented style. On the other hand the existence of the independent decisionmaking style can be interpreted with the CEOs practicing that style have been carrying on in the old way - by using the accustomed methods and measures.

The authors consider one of the most interesting outcomes that a number of Estonian entrepreneurs, who were classified as belonging to the "softer" (also considered more evolved) leadership styles, pointed out the need to be actually tougher, to use more authoritybased style etc. Doubtlessly, this can be interpreted, on the one hand, as a natural situation, where the manager could sometimes find it necessary to use a different style of leadership - yet the question remains, why the need to appeal to the "lower" rather than the "higher" principles prevailed in the interviews. To some extent this could be explained with the transition country context typical of Estonia: a situation described earli- er, where the general uncertainty inevitably dictates the certain type of behaviour possible for the manager and it cannot be ruled out that the situations requiring "tougher" managers have not ended.

All in all it is important to emphasise that transition countries certainly cannot be judged in a uniform and general manner; that they are in a constant movement from authority and individual-centred styles towards increasingly "softer" cooperation-based styles. Which style predominates at any given moment depends besides the general environment on the development stage of the enterprise itself and the CEO's personal principles and views, the factors influencing their development etc. In principle, there will always be users of different styles of leadership, since the various contexts, development stages of organisations etc. will by themselves presume various styles of leadership. Therefore, considering also the respondents' wishes to be "tougher" and more self-centred than "softer" and cooperative, it is as yet too early to claim, in which direction the Estonian CEOs are actually moving and which style could be expected to emerge in the future. 


\section{REFERENCES}

Alt, R., Alas, R., Catana, D., Lang, R., Steyrer, J., and Tuulik, K. (2003), Leadership in Transformation - Between Local Embeddedness and Global Challenges, EBS Review, Autumn, No. 17, pp. 4051.

Bales, R. F. (1950), Interaction process analysis: A method for the study of small groups. Reading, MA: Addison-Wesley.

Bass, B. M. (1985), Leadership and performance beyond expectations. New York: Free Press.

Bass, B, M. (1998), Transformational leadership: Industrial, military, and educational impact. Mahwah, New York: Erlbaum.

Bass, B. M., and Steidlmeier, P. (2004), Ethics, character, and authentic transformational leadership behavior. In Ciulla, J. B. (Ed.) Ethics, the heart of leadership. Praeger. Pp. 175-196.

Bennis, W.G, and Nanus, B. (1985), Leaders: The strategies for raking charge. New York: Harper \& Row.

Burns, J. MG. (1978), Leadership. New York: Harper \& Row.

Ciulla, J. B. (2004), Leadership and the problems of bogus empowerment. In Ciulla, J. B. (Ed.) Ethics, the heart of leadership. Praeger. Pp. 59-82.

Clark, E., and Soulsby, A. (1999), Organizational Change in Post-Communist Europe: Management and transformation in the Czech Republic,

Routledge.

Eagly, A. H. and Johannesen-Schmidt, M. C. (2001), The Leadership Styles of Women and Men. Journal of Social Issues, 57( 4), pp. 781-797.

George, B. (2003), Authentic Leadership:

Rediscovering the secrets to creating lasting value.

Jossey-Bass.

Ginnett, R. C. (1996), Team effectiveness leadership model: identifying leverage points for change. Proceedings of the 1996 National Leadership Institute Conference. College Park, MD: National Leadership Institute

Greenleaf, R. K. (2002), Servant Leadership. A
Journy into the Nature of Legitimate Power \& Greatness. New York/Mahwah, N. J.: Paulis Press.

House, R. J., and Aditya, R. N. (1997), The Social Scientific Study of Leadership: Quo Vadis? Journal of Management, 23(3), pp. 409-473.

House, R.J., Hanges P. J., Javidan M., Dorfman P. W., and Gupta V. (Eds) (2004), Culture, Leadership, and Organizations, The GLOBE Study of 62 Societies, Sage Publications, Inc.

Kotter, J. P. (1990), A force for Change: How leadership differs from management. New York: Free Press.

Kanungo, R. N., and Mendonca, M. (Eds) (1996), Ethical dimensions of leadership. Thousand Oaks : Sage Publications.

Spears, L. C. (1998), Tracing the growing impact of servant-leadership. In L. C. Spears (Ed.) Insights on leadership : service, stewardship, spirit and servant leadership/ - New York : John Wiley \& Sons, pp. 112.

Stogdill, R. M. (1974), Handbook of leadership: A survey ofthe literature. New York: Eree Press.

Yukl, G. (1989), Managerial Leadership: A Review of Theory and Research. Journal of Management, 15(2), pp. 251-289. 